\title{
Patterns of Database Use in Academic Libraries
}

\section{Carol Tenopir and Eleanor Read}

\begin{abstract}
Database usage data from a random sample of academic libraries in the United States and Canada reveal patterns of use in selected types of libraries. Library users tend to use commercial online databases most frequently early in the week, at midday, and at times that correspond to the academic calendar (November in this six-month sample). On average, relatively low numbers of users are simultaneously logged on to research databases at any size of library. A questionnaire sent to these same libraries identified many other factors that might influence database use, including level of instruction, availability of remote log-in, and placement of a database on the library's home page, although none of these factors was found to be statistically significant.
\end{abstract}

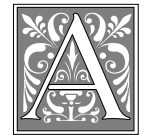

cademic librarians today must consider many factors when making the difficult decisions about what electronic resources to purchase for their users. Their decisions are based not merely on determining what content is best or most unique or even what system offers the most user-friendly or most powerful access software. To best allocate budgets and select the options that will serve the greatest number of users, librarians also must weigh pricing options and licensing restrictions and predict likely levels of use for each database selected. Predicting usage patterns and levels of use is difficult, but important, because prices or licensing restrictions are often based on amount of use, total number of potential users, or number of simultaneous searchers allowed.

Predicting likely numbers of simultaneous users is especially difficult without a history of prior usage. The library that is leasing a new product or offering online access for the first time often has to guess how much the database will be used. However, usage data from other academic libraries may help similar libraries to predict levels and patterns of use.

This paper reports on a two-phase study of academic libraries to identify patterns of database use and the factors that might influence this use. Online data captured from ninety-three academic libraries reveal how many users are logged

Carol Tenopir is a Professor in the School of Information Sciences at the University of Tennessee; e-mail: ctenopir@utk.edu. Eleanor Read is a Graduate Research Assistant in the School of Information Sciences at the University of Tennessee; e-mail: eread@utk.edu The authors would like to thank Danielle M. Green for her able assistance and Cari Springer for her statistical consulting. George Banks and Leslie Preston were involved in the project at its early stages, especially in the overwhelming task of figuring out how to deal with tens of millions of online data points and to present the data in a meaningful way. Shawn Collins, technology coordinator at the School of Information Sciences, has offered expert support throughout. 
on simultaneously to selected online research databases and what time of day, week, and month academic users are searching most often. Examination of these patterns will help other academic libraries negotiate simultaneous usage licenses and estimate the number of workstations and ports required.

\section{The researchers asked each library about its specific environment for online access and gathered informa- tion about factors that may influence online use.}

However, usage data do not show what each individual library is doing, if anything, to encourage use of these databases, so the usage data were supplemented with a survey. The researchers asked each library about its specific environment for online access and gathered information about factors that may influence online use.

\section{Review of the Literature}

The ALA's Office for Research and Statistics participates in studies regularly to gauge amounts of library use. In 1997, in cooperation with ACRL, ALA published a survey that showed how all types of academic libraries have embraced electronic services, although the survey did not consider when the resources were being used or how libraries measured use. ${ }^{1}$

Earlier usage studies for automated resources often were done to help libraries determine how many terminals were required when they first brought up an online catalog (just as even earlier studies tried to predict an appropriate number of chairs to provide in the library). A 1983 report incorporated queuing models to recommend appropriate numbers of terminals for online catalogs. ${ }^{2}$ Turnstile counts have been used to optimize reference department staffing or pickup schedules for shelving. These show that peak usage periods in academic libraries correspond to the academic calendar and daily class schedules. ${ }^{3,4}$
To improve user services, specific libraries often focus on how electronic resources are used by their patrons. The Biological Sciences Library of The Ohio State University, for example, conducted a four-and-a-half-year study of the use of CD-ROM databases in its library. It found that a majority of users recorded all use within a one-month period and more than a third of all users recorded all use on only one day. ${ }^{5}$ The New York Public Library Research Libraries compared patterns for remote usage of their OPAC with patterns of usage from within the libraries. They found that patterns for remote searching of the OPAC are distributed more evenly over each day and within each week than in-library searching and that a "large part of remote searching occurred when the Research Libraries were closed." ${ }^{\prime 6}$ In a call for better computerized monitoring of remote users, Thomas A. Peters discussed the widespread belief that remote users will likely follow "diurnal" usage patterns but suggested that this may only be true in metropolitan areas "already noted for diurnally diffuse human behavior." ${ }^{\prime 7}$

However, data such as turnstile counts or other measures of amount of use are not enough to see why a particular resource is used. Anne-Marie Belanger and Sandra D. Hoffman surveyed academic library users to see if demographic or other factors influence how often they use ERIC on CDROM. ${ }^{8}$ Judith A. Adams and Sharon C. Bonk found that, for faculty, not knowing what electronic resources are available is the major barrier to use. Faculty believe that training classes for electronic resources are a high-priority need. ${ }^{9}$ Charles $\mathrm{T}$. Townley and Leigh Murray found in a study of six southwestern academic libraries that database use does not fit a predictable pattern across libraries and databases. Database use is influenced by the length of time the database has been available (available more than one year promotes heaviest use), limiting the forms of access to the database, the source of the database (locally loaded and Internet-based databases were preferred), and the availability of user instruction in the library. ${ }^{10}$ 
Librarians' attitudes or factors such as convenience, accessibility of a database through menu screens, or the availability of training materials might be expected to influence the amount of use that any specific resource such as an online database receives. Carol Tenopir and Lisa Ennis analyzed reference librarians' attitudes toward electronic reference products and changes in university reference services throughout the 1990s. ${ }^{11,12}$ Reference rooms in libraries grew busier throughout the decade. Many more workstations were added in libraries, while at the same time remote access was made widely available. Librarians reported that users prefer electronic reference products over print, both from within the library and through dial-up access; and library instruction classes now most often focus on electronic resources. End-user online searching of commercial databases is now an integral part of library reference services and users have come to expect online access through their libraries. Reference librarians in these research libraries feel busy but, for the most part, have positive attitudes toward technology.

Collection development and reference librarians now spend much of their time evaluating and selecting online resources, a task more complex than, but not unlike, traditional selection and collection building. Added to the traditional task of evaluating quality, content, coverage, and ease of use is the need to select the best possible pricing options from among many alternatives and to negotiate online licensing agreements. ${ }^{13,14}$ The best pricing option varies from library to library and, within a library, may be different for heavily used resources than for those used less often.

Many online resources are purchased with some type of user-based license. In simultaneous usage licenses, librarians must commit to how many online users will be permitted to be connected at any one time to a given database or a family of databases. Providing for too many simultaneous users will waste the library's money and allowing too few will cause frustration among users who must wait to access a desired database.

The information reported here is part of a larger study that examines patterns and factors of use for both academic and public libraries. ${ }^{15}$ This study demonstrates that although the exact amount of use varies with the size and type of library, the usage patterns in academic and public libraries are similar. Although all libraries have some unique situations, learning from other, similar libraries may be the best way to estimate how many users will likely use a database and when that usage will occur. The usage pattern data in this study were first reported in 1999. ${ }^{16,17}$ (The present article updates, corrects, and expands on some of the data in these earlier reports.) Usage data show how often online databases are used in academic libraries; the survey information begins to look at why they are used.

\section{Methodology: Phase 1-Usage Data}

Measuring online usage is more complex than collecting turnstile counts, sampling workstation queues, or even measuring access to a single library's online catalog. Online use from many libraries searching comparable databases must be captured over a period of time to give a broad picture that will allow prediction of patterns for individual libraries. To get both remote and in-house online activity for commercial databases from many libraries, a major database producer and aggregator agreed to provide the researchers with usage data for all of its online databases. This database aggregator provides online access to many bibliographic, full-text, and directory databases, thirty-eight of which were used by one or more academic libraries in this study.

This database aggregator provides more than a hundred database titles, many of which contain overlapping information aimed at different audiences. For example, the same journals and magazines may be available in an indexingonly version, a full-text version, or a combination version. Versions indexing thousands of titles may be sold to university 
libraries; small colleges may prefer versions with fewer, selected titles. Rarely does the same library purchase overlapping titles, although a library may purchase separate current and backfile versions or choose a combined version. Some databases are subject specific (business journals, for example); others are aimed at a general interest academic audience.

Online usage for every library is captured automatically by the database provider in five-minute intervals, twenty-four hours a day.

A random sample of a hundred academic libraries in the United States and Canada was taken from this company's list of more than 1,200 libraries. From this sample, usable online usage data were available for ninety-three libraries. The ninety-three libraries represent every Carnegie Class of parent academic institution, with the largest number being from Master's Universities and Colleges I. Table 1 shows how Carnegie Class was distributed in the study sample. For purposes of analysis, similar Carnegie Classes are reported together. All data are reported in the following six groups: Baccalaureate Colleges, Master's Universities and Colleges, Doctoral Universities, Research Universities, Associate of Arts Colleges, and Schools of Business and Management.

Online usage for every library is captured automatically by the database provider in five-minute intervals, twenty-four hours a day. Even with a sample of only ninety-three libraries, a year's worth of data would yield more than ten million data points for every database. Therefore, for this study, usage data were sampled once per hour (on each half-hour), for sixteen hours per day (8 a.m. to midnight, eastern time), for a period of six months (July to December 1997), resulting in more than 282,000 data points per database. To report all sample times in local time, the researchers have converted the hourly data into the local time for each library and taken into account daylight savings time for those areas that observe it. Because the database company's computer was set to eastern time, data from libraries in western time zones begin and end earlier.

Usage data reveal how many simultaneous users are logged on to any one database at any of the sampled times. Time

\begin{tabular}{|lcc|}
\hline \multicolumn{3}{c|}{ TABLE 1 } \\
Carnegie Categories for Academic Institutions \\
\hline \hline Carnegie Class & No. in Sample & Surveys Received \\
\hline Baccalaureate Colleges & $\mathbf{1 6}$ & $\mathbf{8}$ \\
Baccalaureate (Liberal Arts) Colleges I & 7 & 3 \\
Baccalaureate Colleges II & 9 & 5 \\
Master's Universities and Colleges & $\mathbf{3 5}$ & $\mathbf{2 2}$ \\
Master's (Comprehensive) Universities and Colleges I & 33 & 21 \\
Master's (Comprehensive) Universities and Colleges II & 2 & 1 \\
Doctoral Universities & $\mathbf{9}$ & $\mathbf{6}$ \\
Doctoral Universities I & 2 & 2 \\
Doctoral Universities II & 7 & 4 \\
Research Universities & $\mathbf{1 8}$ & $\mathbf{1 1}$ \\
Research Universities I & 14 & 6 \\
Research Universities II & 4 & 5 \\
Associate of Arts Colleges & $\mathbf{1 2}$ & 7 \\
Schools of Business and Management & $\mathbf{3}$ & $\mathbf{3}$ \\
\hline Total & $\mathbf{9 3}$ & $\mathbf{5 7}$ \\
Source: www.carnegiefoundation.org & & \\
\hline
\end{tabular}




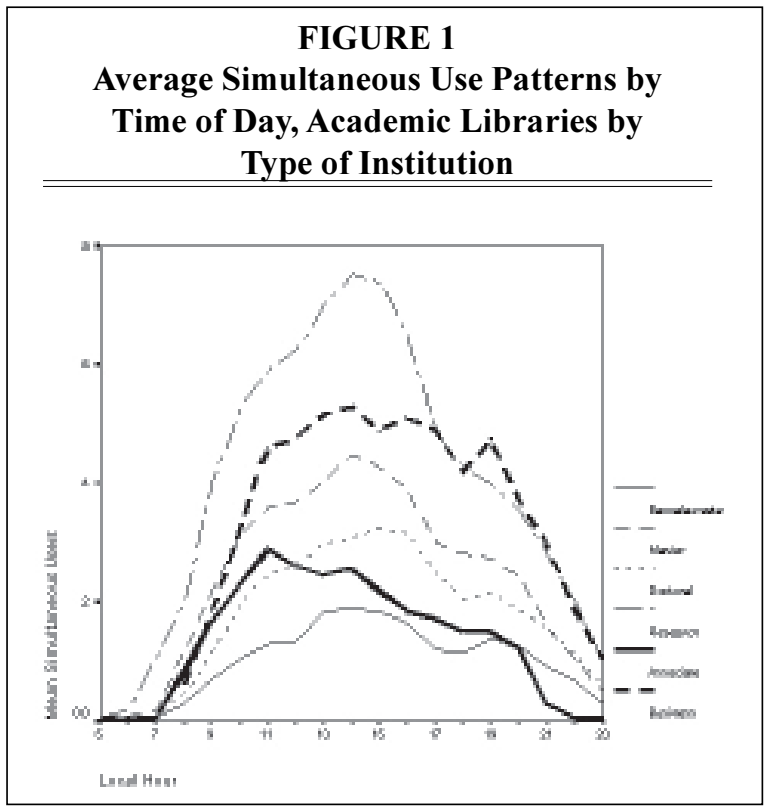

sought by sending a questionnaire to each of the academic libraries in the sample. Survey questions were grouped in four categories: (1) Information about Your Library; (2) Information about the Databases You Provide; (3) Information about Databases from ... [the aggregator]; and (4) Other Factors. Fifty-seven libraries responded and all Carnegie Classes were represented, as shown in table 1.

\section{Analysis of Usage Patterns}

The number of simultaneous users for all thirty-eight databases in all ninety-three libraries ranges from zero us-

stamps on the data allow patterns to be drawn that show average numbers of users by time of day, day of the week, and month for each class of library and each database or database group.

In this analysis, the thirty-eight databases used by the libraries were examined in four different groupings: (1) all thirtyeight databases together; (2) eight databases that together cover general magazines and journals for academic libraries (including full-text, indexing-only, backfiles, and current files); (3) the single most-used database among these academic libraries (a current general magazine and journal title); and (4) eleven directory or bibliographic databases that specialize in business information.

\section{Methodology: Phase 2- Questionnaires}

Usage data reveal typical patterns of use within classes of academic libraries but do not identify why or how the specific environment might influence online use. To begin to answer the questions of how and why, information beyond usage data is needed. Information about unique environmental factors that may influence online use in individual libraries was ers (the mode and median) to sixty-six users (the mean is .28 and the standard deviation is 1.37). Not surprisingly, online usage in academic libraries follows the regular rhythms of academic life. Although the range and exact number of users vary by class of library, the patterns of use, including peaks and valleys, are quite similar. The busiest time for online research in or from academic libraries is between 11 a.m. and 5 p.m. (local time), on Mondays and, to a slightly lesser degree, Tuesdays, in November. (It is likely that April and May also would be high-use months as the spring semester is coming to an end.) Use in all types of libraries dips in August and then begins a steady rise through the semester until after November.

Although these usage patterns correspond to the peak hours for library use, 75 percent of these libraries also offer remote online access. It appears that not many college students choose to be working online at times other than the normal hours that the physical library is open, even if they can be working from a dormitory, office, campus lab, or home. Figures 1,2, and 3 show these patterns of use aggregated for all databases, but separated by type of institution. 


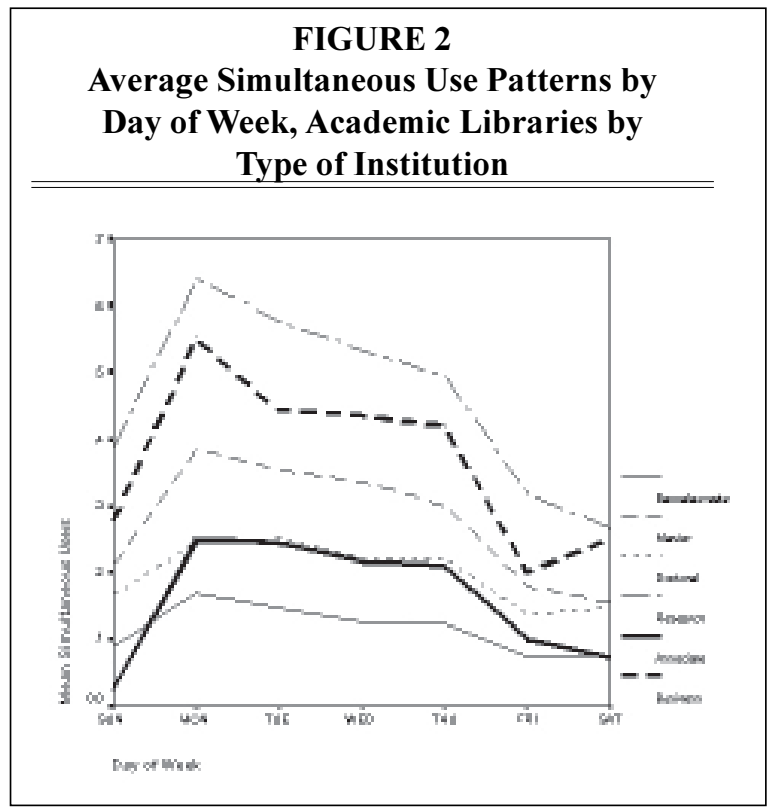

ter job by helping to identify times of heavy demand. Another way to show impact is to measure how often multiple users are logged on. Tables 2, 3, 4, and 5 show how many simultaneous users are logged on at any one time for all databases (table 2 ), the eight general interest databases (table 3), the single most-used database (table 4), and finally, the business databases (table 5). (Note that the tables do not include every discrete number of users.)

Unlike use of a library's catalog, simultaneous usage of a reference database is relatively uncommon. Providing access to only one

Patterns of use for eight general databases together show similar patterns of use (figures 4, 5, and 6). The mode and median are zero, but the mean is .56 and standard deviation is 2.15 . The patterns of use for the single most-used general database and the eleven business databases are very similar and so are not presented here. However, amounts of use are higher and vary more for the single most-used database, with a mean of .84 simultaneous users and a standard deviation of 2.77 (the mode and median are zero). As might be expected, the amount of simultaneous use for business databases is higher for schools of business than for other types of institutions. The overall mean for business databases is .14 , with a standard deviation of .57 (the mode and median are zero).

Average numbers of users do not show the true impact of multiple users on workstations, online ports, and staff. Patterns do a bet- user for a general research database, for example, would be satisfactory 82.8 percent of the time in research libraries and 95.2 percent of the time in baccalaureate colleges. Allowing five simultaneous users would be satisfactory 94.9 percent of the time in research libraries and 99.8 percent of the time in baccalaureate institutions (table 3).

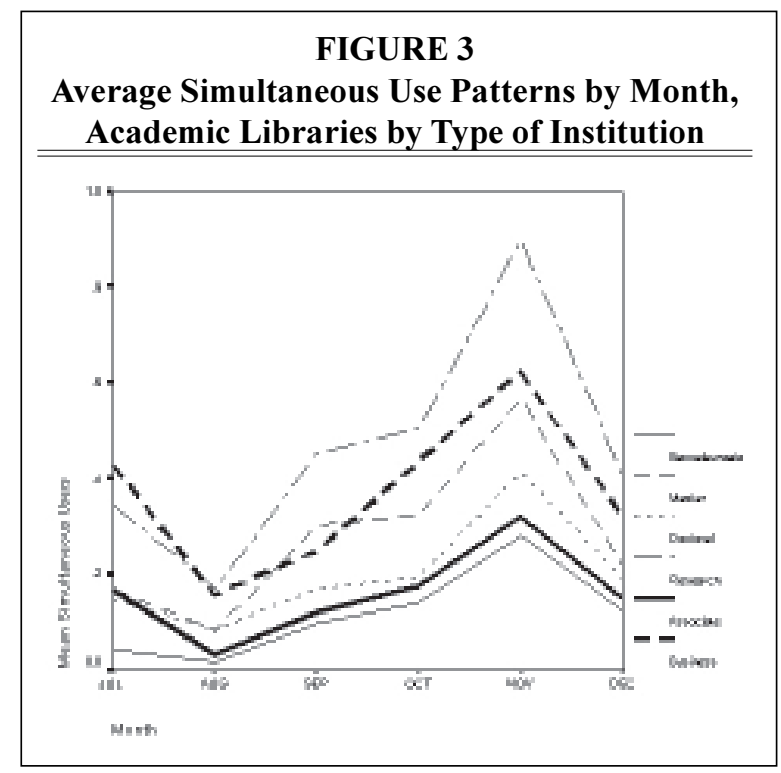


The single most-used database in these libraries also was analyzed alone to mitigate any effects on the data from seldom-used files, such as backfiles. Table 4 shows the simultaneous use figures for the general magazine/journal database used most often in these libraries. Clearly, databases that are expected to be used by students and faculty in a variety of academic disciplines and that have general, currentevent appeal will attract more simultaneous users. Providing access to only one user for this database, for example, would be satisfactory only 76.4 percent of the time in research universities and 93.8 percent of the time in baccalaureate colleges. If be accommodated 99.7 percent of the time five simultaneous users were provided for, baccalaureate institution users would and research library users 91.6 percent of the time.

FIGURE 4

Average Simultaneous Use Patterns by Time of Day, Magazines and Journals for Academic Libraries, Academic Libraries by Type of Institution

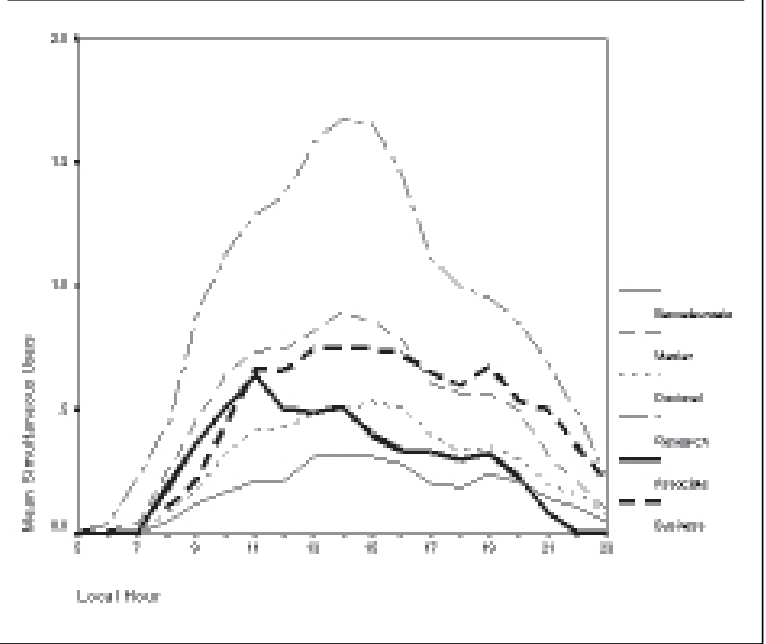

FIGURE 5

Average Simultaneous Use Patterns by Day of Week, Magazines and Journals for Academic Libraries, Academic Libraries by Type of Institution

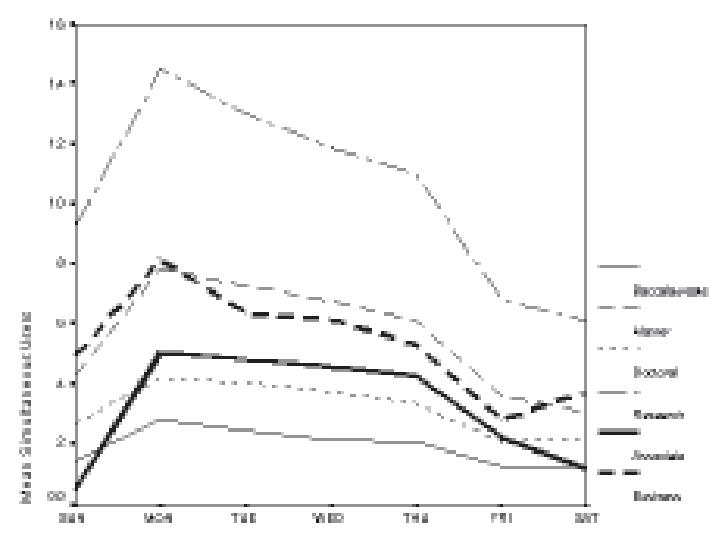

bus of with
However, when selecting a maximum number for simultaneous use capability, the law of diminishing returns applies. A satisfaction rate of 99.5 percent could be achieved with four simultaneous users in baccalaureate college libraries and with twenty-two simultaneous users in research libraries, but to achieve 100 percent satisfaction would necessitate eighteen simultaneous users in baccalaureate college libraries and sixty-six in research libraries (table 4). Aiming for 100 percent satisfaction is neither reasonable nor cost beneficial.

In using these usage charts to determine number of users for a simultaneous use contract, librarians should consider not only the 


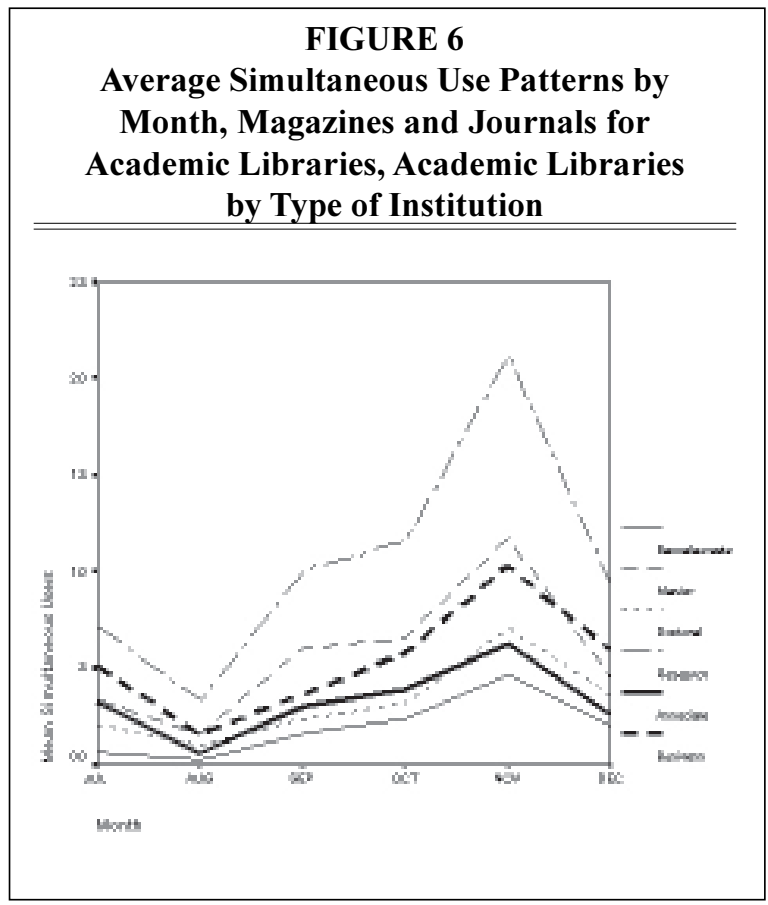

time at each academic library based on student enrollment. As might be expected, the number of simultaneous users required generally increases as the student population increases. The exception to this rule, shown in table 6 for schools with 45,000 to 89,999 students, should be interpreted with caution because it is based on data from only two universities.

\section{Analysis of Questionnaires}

The fifty-seven libraries that responded to the questionnaire offer a variety of electronic media for end-user searching. More than 90 percent offer CD-ROM, commercial online, or World Wide Web access. Many pro-

class of their institution, but also the type of database they are purchasing. In most academic libraries, general interest titles will get more use than more specialized databases. For example, as shown in table 5 , most types of libraries could achieve 98 to 99 percent satisfaction rates for business database by accommodating only two simultaneous users. Not surprisingly, business colleges are an exception, requiring the capacity for six simultaneous users to achieve 99 percent satisfaction.

Multipurpose workstations that allow access to the library's online catalog and other online databases are the rule.

Carnegie Class is one way to categorize academic libraries; number of students enrolled is another. This is an important distinction because not all institutions within the same Carnegie Class have the same number of students. Table 6 accounts for this difference by showing how many simultaneous users are required to meet demand 99 percent of the vide access to several commercial online services (table 7).

In terms of the ways libraries influence database use, 75 percent provide remote access in addition to in-house access (table 8). Approximately 95 percent of the libraries that responded to the survey offer access to the reference databases on ten or more workstations (data not shown). Eighty-eight percent of the libraries offer access to this company's databases on three-quarters or more of their public workstations, but only five percent have workstations dedicated to these databases. Multipurpose workstations that allow access to the library's online catalog and other online databases are the rule.

Many librarians believe that the databases analyzed in this study are among some of the most popular with library users. The largest number of libraries (46\%) reported that these are the most popular databases (libraries in six of the ten Carnegie Classes said they were the most popular). An additional 21 percent believe these databases rank second in popularity (data not shown). Some libraries actively 


\begin{tabular}{|c|c|c|c|c|c|c|c|}
\hline \multicolumn{8}{|c|}{$\begin{array}{c}\text { TABLE } 2 \\
\text { Simultaneous Use for All Databases Aggregated } \\
\end{array}$} \\
\hline \multicolumn{2}{|c|}{ No. of Users } & \multicolumn{5}{|c|}{$\begin{array}{c}\text { Cumulative Percentage } \\
\text { Type of Institution (Carnegie Class) }\end{array}$} & \multirow{3}{*}{$\begin{array}{c}\text { Overall } \\
94.2\end{array}$} \\
\hline & Bacc. & Master's & Doctoral & Research & Associate & Business & \\
\hline 1 & 97.3 & 94.5 & 95.4 & 91.5 & 96.1 & 90.5 & \\
\hline 2 & 98.9 & 96.9 & 98.1 & 94.7 & 98.2 & 94.9 & 96.8 \\
\hline 3 & 99.5 & 98.1 & 99.1 & 96.5 & 99.2 & 97.3 & 98.1 \\
\hline 4 & 99.8 & 98.8 & 99.5 & 97.5 & 99.6 & 98.6 & 98.8 \\
\hline 5 & 99.9 & 99.2 & 99.7 & 98.2 & 99.8 & 99.3 & 99.2 \\
\hline 6 & 99.9 & 99.4 & 99.8 & 98.7 & 99.9 & 99.7 & 99.4 \\
\hline 7 & 99.9 & 99.5 & 99.9 & 99.0 & 99.9 & 99.9 & 99.6 \\
\hline 8 & 99.9 & 99.6 & 99.9 & 99.2 & 99.9 & 99.9 & 99.7 \\
\hline 9 & 99.9 & 99.7 & 99.9 & 99.4 & 99.9 & 99.9 & 99.7 \\
\hline 10 & 99.9 & 99.7 & 99.9 & 99.5 & 99.9 & 99.9 & 99.8 \\
\hline 15 & 99.9 & 99.9 & 99.9 & 99.7 & 99.9 & 99.9 & 99.9 \\
\hline 25 & - & 99.9 & - & 99.9 & 99.9 & - & 99.9 \\
\hline \multicolumn{8}{|c|}{ Maximum Simultaneous Users } \\
\hline$(10$ & 18 & 55 & 24 & 66 & 35 & 23 & 66 \\
\hline
\end{tabular}

promote one or more of these databases or, at least, make these databases easier to find. Of the libraries that responded to the survey, 66 percent note these specific databases on the library system's main menu, nearly 20 percent post signs that promote them, 60 percent provide handouts that de- scribe them, and 82 percent offer training that specifically mentions this company's databases (table 8). After a user logs in or sits down at a workstation, just one to three steps are required to reach the databases in at least 87 percent of the libraries (data not shown).

TABLE 3

Simultaneous Use for Magazines and Journals for Academic Libraries

No. of Users Cumulative Percentage

Type of Institution (Carnegie Class)

\begin{tabular}{cccccccc}
\hline & Bacc. & Master's & Doctoral & Research & Associate & Business & Overall \\
1 & 95.2 & 89.2 & 92.3 & 82.8 & 91.7 & 85.6 & 89.1 \\
2 & 97.9 & 93.0 & 96.1 & 87.7 & 95.6 & 92.0 & 93.1 \\
3 & 99.1 & 95.4 & 97.9 & 91.0 & 97.7 & 95.9 & 95.4 \\
4 & 99.6 & 96.9 & 98.8 & 93.3 & 98.9 & 98.1 & 96.9 \\
5 & 99.8 & 97.8 & 99.3 & 94.9 & 99.4 & 99.1 & 97.8 \\
6 & 99.9 & 98.4 & 99.6 & 96.1 & 99.7 & 99.6 & 98.4 \\
7 & 99.9 & 98.8 & 99.8 & 97.0 & 99.8 & 99.8 & 98.8 \\
8 & 99.9 & 99.0 & 99.9 & 97.7 & 99.9 & 99.9 & 99.0 \\
9 & 99.9 & 99.2 & 99.9 & 98.1 & 99.9 & 99.9 & 99.2 \\
10 & 99.9 & 99.3 & 99.9 & 98.4 & 99.9 & 99.9 & 99.3 \\
15 & 99.9 & 99.6 & 99.9 & 99.0 & 99.9 & 99.9 & 99.6 \\
25 & - & 99.9 & - & 99.6 & 99.9 & - & 99.8 \\
\hline \multicolumn{7}{l}{ Maximum Simultaneous Users } \\
$(100 \%)$ & 18 & 55 & 24 & 66 & 35 & 22 & 66 \\
\hline
\end{tabular}




\section{TABLE 4}

Simultaneous Use for the Most-Used Database (General Magazine/Journal)

No. of Users

Cumulative Percentage

Type of Institution (Carnegie Class)

\begin{tabular}{cccccccc}
\hline & Bacc. & Master's & Doctoral & Research & Associate & Business & Overall \\
1 & 93.8 & 84.3 & 87.6 & 76.4 & 86.7 & 85.3 & 84.7 \\
2 & 97.4 & 89.6 & 93.3 & 82.1 & 92.6 & 92.2 & 90.0 \\
3 & 98.9 & 93.1 & 96.2 & 86.2 & 96.0 & 96.1 & 93.2 \\
4 & 99.5 & 95.3 & 97.8 & 89.3 & 98.1 & 98.1 & 95.2 \\
5 & 99.7 & 96.6 & 98.7 & 91.6 & 99.1 & 99.1 & 96.5 \\
6 & 99.9 & 97.5 & 99.2 & 93.4 & 99.5 & 99.5 & 97.4 \\
7 & 99.9 & 98.0 & 99.6 & 94.8 & 99.7 & 99.7 & 97.9 \\
8 & 99.9 & 98.3 & 99.8 & 95.8 & 99.8 & 99.9 & 98.4 \\
9 & 99.9 & 98.6 & 99.9 & 96.5 & 99.9 & 99.9 & 98.6 \\
10 & 99.9 & 98.8 & 99.9 & 97.0 & 99.9 & 99.9 & 98.8 \\
15 & 99.9 & 99.3 & 99.9 & 98.2 & 99.9 & 99.9 & 99.3 \\
25 & - & 99.7 & - & 99.2 & 99.9 & - & 99.7 \\
\hline Maximum Simultaneous Users & & & & & \\
$(100 \%)$ & 18 & 55 & 24 & 66 & 31 & 22 & 66 \\
\hline
\end{tabular}

Close ties with academic classes also should influence how often a database is used. Three-quarters of the libraries said that all of this company's databases they subscribe to have subject matter related to academic classes and all of the libraries said that at least some are class related. Although many librarians do not know for sure if the databases are mentioned in academic classes, 66 percent reported that they are mentioned specifically and 58 percent said that specific class assignments require use of the databases.

Although database use undoubtedly is influenced somehow by library policies, none of these factors proved to be statis-

\section{TABLE 5}

Simultaneous Use for Business Directories and Periodicals

No. of Users

Cumulative Percentage

Type of Institution (Carnegie Class)

\begin{tabular}{cccccccc}
\hline & Bacc. & Master's & Doctoral & Research & Associate & Business & Overall \\
1 & 99.3 & 97.4 & 95.8 & 95.2 & 98.7 & 84.2 & 96.7 \\
2 & 99.9 & 99.1 & 98.7 & 98.1 & 99.6 & 90.9 & 98.7 \\
3 & 99.9 & 99.7 & 99.6 & 99.4 & 99.9 & 94.8 & 99.5 \\
4 & 99.9 & 99.9 & 99.8 & 99.8 & 99.9 & 97.1 & 99.8 \\
5 & 100.0 & 99.9 & 99.9 & 99.9 & 99.9 & 98.5 & 99.9 \\
6 & - & 99.9 & 99.9 & 99.9 & 99.9 & 99.4 & 99.9 \\
7 & - & 99.9 & 99.9 & 99.9 & 99.9 & 99.7 & 99.9 \\
8 & - & 99.9 & 99.9 & 99.9 & 99.9 & 99.8 & 99.9 \\
9 & - & 99.9 & 99.9 & 99.9 & 99.9 & 99.9 & 99.9 \\
10 & - & 99.9 & 99.9 & 99.9 & 99.9 & 99.9 & 99.9 \\
15 & - & 99.9 & 99.9 & 99.9 & 99.9 & 99.9 & 99.9 \\
25 & - & 99.9 & - & 99.9 & - & - & 99.9 \\
\hline \multicolumn{7}{l}{ Maximum Simultaneous Users } \\
$(100 \%)$ & 5 & 28 & 20 & 29 & 17 & 23 & 29 \\
\hline
\end{tabular}




\begin{tabular}{|ccc|}
\hline \multicolumn{3}{c|}{ TABLE 6 } \\
Number of Simultaneous Users for 99 Percent Coverage \\
\hline \hline $\begin{array}{c}\text { No. of Students } \\
\text { Enrolled }\end{array}$ & $\begin{array}{c}\text { No. of Libraries } \\
\text { in Enrollment Group }\end{array}$ & $\begin{array}{c}\text { No. of Simultaneous Users } \\
\text { Needed for } 99 \text { Percent Coverage }\end{array}$ \\
\hline $1-2,499$ & 13 & 2 \\
$2,500-4,999$ & 15 & 3 \\
$5,000-7,499$ & 16 & 4 \\
$7,500-9,999$ & 7 & 4 \\
$10,000-14,999$ & 15 & 5 \\
$15,000-19,999$ & 7 & 5 \\
$20,000-24,999$ & 7 & 7 \\
$25,000-44,999$ & 8 & 7 \\
$45,000-89,999$ & 2 & 4 \\
90,000 or more & 2 & 27 \\
\hline
\end{tabular}

tically correlated to amount of use. In order to take into account the size of the student population in statistical testing, a variable for average use per 10,000 students was created. Because these new data normally were not distributed, the nonparametric Mann-Whitney and Kruskal-Wallis tests were employed to test for effects on usage. The independent variables tested included: availability of remote log-in, number of workstations provided, whether the aggregator's databases were noted on the main menu, number of steps required to reach the databases, whether signs were posted, whether handouts were available, and percentage of workstations that allowed the company's databases to be searched.

\section{Conclusions}

Knowing when and how different types of databases are likely to be used in any library will help librarians determine appropriate levels for simultaneous use contracts, optimum number of usage ports, and how staffing can best be assigned. It will come as no surprise to academic reference librarians that peak online usage follows clearly defined patterns. The greatest number of users is online early in the week, at midday, in the month when term papers are due. A majority of

TABLE 7

Electronic Media for End Users

\begin{tabular}{|c|c|c|c|c|c|c|c|}
\hline \multirow[t]{2}{*}{$\begin{array}{l}\text { Media Types Used } \\
\text { by Respondents }\end{array}$} & \multicolumn{7}{|c|}{$\begin{array}{c}\text { Percentage } \\
\text { Type of Institution (Carnegie Class) }\end{array}$} \\
\hline & $\begin{array}{r}\text { Bacc. } \\
87.5\end{array}$ & $\begin{array}{l}\text { Master's } \\
100.0\end{array}$ & $\begin{array}{r}\text { Doc. } \\
100.0\end{array}$ & $\begin{array}{l}\text { Res. } \\
100.0\end{array}$ & $\begin{array}{l}\text { Assoc. } \\
85.7\end{array}$ & $\begin{array}{r}\text { Bus. } \\
100.0\end{array}$ & $\begin{array}{c}\text { Overall } \\
96.5\end{array}$ \\
\hline Locally loaded & 12.5 & 31.8 & 33.3 & 63.6 & 57.1 & 33.3 & 38.6 \\
\hline $\begin{array}{l}\text { Loaded on another } \\
\text { library's compute } \\
\text { Commercial online }\end{array}$ & 75.0 & 31.8 & 50.0 & 36.4 & 28.6 & 33.3 & 40.4 \\
\hline $\begin{array}{l}\text { from a vendor } \\
\text { Commercial online } \\
\text { from an OPAC }\end{array}$ & 100.0 & 95.5 & 100.0 & 100.0 & 71.4 & 100.0 & 94.7 \\
\hline company & 25.0 & 27.3 & 0.0 & 27.3 & 14.3 & 33.3 & 22.8 \\
\hline World Wide Web & 87.5 & 100.0 & 83.3 & 90.9 & 100.0 & 33.3 & 91.2 \\
\hline
\end{tabular}


TABLE 8

Ways Libraries Influence Database Use

\section{Influential Factors}

Remote access

Workstations

dedicated to

these databases

Databases noted on

library system's

main menu

87.5

Signs

25.0

Handouts

12.5

\section{Bacc. Master's Doc.}

$\begin{array}{lll}62.5 & 85.7 & 100.0\end{array}$

0.0

0.0

66.7

50.0

33.3

71.4

Databases mentioned

specifically in

training

Databases mentioned

specifically in

academic classes $\quad 75.0$

Specific class assignments

require use of these

databases

50.0

$90.5 \quad 83.3$

75.0

66.7
33.3
Percentage

(Carnegie Class)

$\begin{array}{cccc}\text { Res. } & \text { Assoc. } & \text { Bus. } & \text { Overall } \\ 81.8 & 28.6 & 66.7 & 75.0\end{array}$

0.0

14.3

33.3

5.0

85.7

33.3

66.1

28.6

19.6

50.0

71.4

66.7

60.0

27.3

71.4

100.0

$\begin{array}{lll}81.8 & 57.1 \quad 100.0\end{array}$

54.5

$57.1 \quad 100.0$ academic users are accessing databases at the time they typically use the library. For all types of academic libraries, there are clear valleys and peaks for online use, following the rhythms of academic life.

Even for general interest magazine databases that are available both in-house and through remote access, often no one is online. Peak usage can be quite high in some libraries, but average usage for any one database or group of similar databases is low. Students may be in chat rooms or surfing the Net at all hours, but few are likely to be searching research databases.

Although none of the variables the researchers tested were found to be statistically significant predictors of amount of use, a combination of factors may influence use, many of which are difficult to measure or capture on a questionnaire. Librarians influence use in a variety of subtle and obvious ways, including mentioning specific products in a user instruction class, advocating use of a specific database in specific class assignments, referring to a database on a library's welcome screen, or otherwise reminding users about a specific database. Although no single reference database may be in use by a large number of simultaneous users day or night, making sure that databases are available most of the time when users need them, and instituting policies that make this access easy, is a responsibility of all academic libraries.

\section{Notes}

1. American Library Association, Electronic Services in Academic Libraries (Chicago: ALA, 1997). [Executive summary is available from www.ala.org/alaorg/ors/elecsvcs.html.]

2. John E. Tolle et al., "Determining the Required Number of Online Catalog Terminals," Information Technology E Libraries 2 (Sept. 1983): 261-65.

3. Marjorie E. Murfin, "National Reference Measurement: What Can It Tell Us about Staff- 
ing," College \& Research Libraries 44 (Sept. 1983): 321-33.

4. William E. McGrath, "Periodicity in Academic Library Circulation: A Spectral Analysis," Journal of the American Society for Information Science 47 (Feb. 1996): 136-45.

5. Bruce A. Leach, "Identifying CD-ROM Use Patterns as a Tool for Evaluating User Instruction," College \& Research Libraries 55 (July 1994): 365-71.

6. Thomas A. Lucas, "Time Patterns in Remote OPAC Use," College \& Research Libraries 54 (Sept. 1993): 439-45.

7. Thomas A. Peters, "Remotely Familiar: Using Computerized Monitoring to Study Remote Use," Library Trends 47, no. 1 (summer 1998): 7-20.

8. Anne-Marie Belanger and Sandra D. Hoffman, "Factors Related to Frequency of Use of CD-ROM: A Study of ERIC in an Academic Library," College \& Research Libraries 51 (Mar. 1990): 153-63.

9. Judith A. Adams and Sharon C. Bonk, "Electronic Information Technologies and Resources: Use by University Faculty and Faculty Preferences for Related Library Services," College \& Research Libraries 56 (Mar. 1995): 119-31.

10. Charles T. Townley and Leigh Murray, "Use-based Criteria for Selecting and Retaining Electronic Information: A Case Study," Information Technology and Libraries 18 (Mar. 1999): 3239.

11. Carol Tenopir and Lisa Ennis, "The Digital Reference World of Academic Librarians," Online 22 (July/Aug. 1998): 22-28.

12. - "The Impact of Digital Reference on Librarians and Library Users," Online 22 (Nov./Dec. 1998): 84-88.

13. Eileen Abels, "Pricing of Electronic Resources: Interviews with Three Vendors," Journal of the American Society for Information Science 47 (Mar. 1996): 235-46.

14. Carol Tenopir, George Banks, and Leslie Preston, "Pricing Options for End User Products in Libraries," in Proceedings of the $1^{\text {th }}$ Annual National Online Meeting, New York, May 12-14, 1998, (Medford, NJ: Information Today, 1998): 419-32.

15. Carol Tenopir and Danielle Green, "Patterns of Use and Usage Factors for Online Databases in Academic and Public Libraries," in Proceedings of the $62^{\text {nd }}$ Annual Meeting of the American Society for Information Science, Washington, D.C., October 31-November 4, 1999, (Medford, NJ: Information Today, 1999): 616-27.

16. Carol Tenopir, "Factors That Influence Database Use," in Proceedings of the Ninth National Conference of the Association of College and Research Libraries, Detroit, April 8-11, 1999, (Chicago: American Library Association, 1999): 68-75.

17. Carol Tenopir and Danielle M. Green, "Simultaneous Usage of Online Databases in Academic and Public Libraries," in Proceedings of the $20^{\text {th }}$ Annual National Online Meeting, New York, May 18-20, 1999, (Medford, NJ: Information Today, 1999): 459-68. 